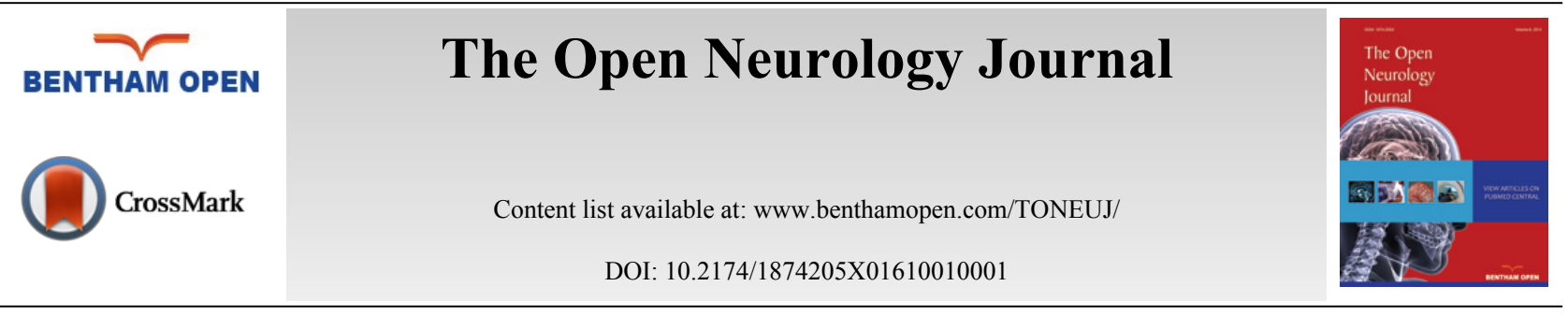

\title{
Postural Control of Healthy Elderly Individuals Compared to Elderly Individuals with Stroke Sequelae
}

\author{
Fábio Marcon Alfieri ${ }^{12^{*}}$, Marcelo Riberto ${ }^{3}$, José Augusto Fernandes Lopes ${ }^{1}$, Thais Raquel Filippo ${ }^{1}$, \\ Marta Imamura ${ }^{1}$ and Linamara Rizzo Battistella ${ }^{1}$ \\ ${ }^{I}$ Clinical Research Center - Institute of Physical Medicine and Rehabilitation, University of Sao Paulo School of \\ Medicine, São Paulo, São Paulo, Brazil \\ ${ }^{2}$ Health Promotion Course and Physical Therapy Faculty - São Paulo Adventist University Center, São Paulo, Brazil \\ ${ }^{3}$ Ribeirão Preto Medical School, University of São Paulo, Brazil
}

\begin{abstract}
A stroke and aging process can modify the postural control. We aimed to compare the postural control of health elderly individuals to that of individuals with stroke sequelae. This cross-sectional transversal study was made with individuals capable of walking without any assistance and that were considered clinically stable. The study had 18 individuals in the group with stroke sequelae (SG) and 34 in the healthy elderly control group (CG). The participants were evaluated for the timed up and go test (TUG) and force platform. The SG showed the worst results in relation to the time of execution of the TUG and the force platform evaluation. The displacement of center of pressure was worse for both groups in the eyes-closed situation, especially in the anteroposterior direction for the CG. The GS showed worse results in the static and dynamic postural control. The healthy elderly showed more dependence on sight to maintain their static balance and there was no difference in the balance tests in relation to the side affected by the stroke.
\end{abstract}

Keywords: Balance, Functional mobility, Older adults, Stroke, Sequelae, TUG.

\section{INTRODUCTION}

Postural control is necessary to perform daily activities and requires the integration of the information from the vestibular, somatosensory, and visual systems to generate a motor response that maintains one's balance in static as well as in dynamic activities [1 - 5].

Alterations in the afferent information as well as musculoskeletal alterations are responsible for the reduction of the postural control among the elderly $[1-3,6,7-11]$. This is exemplified by the fact that approximately $65 \%$ of the individuals older than 60 years frequently feel some dizziness or loss of balance [12].

Aging, associated with some health problem, as well as an alteration of the normal brain function, can affect the postural control of elderly individuals even more. One condition that affects the proper functioning of the brain is a stroke.

Some examples of symptoms that occur in isolated or combined form are: visual alteration, dysarthria, cognitive alteration, mental confusion, dysphasia, disorientation, negligence, memory disturbances, cephalea, deafness, weakness, or sensory loss on one side of the body [13 - 17]. It is known that hemiparesis is the most frequent neurological deficit after a stroke and that hemiparetic patients frequently show balance disturbances [18]. Hemiplegic or hemiparetic individuals show more body oscillation, asymmetric distribution of body weight, and a reduction of their capacity for stability [19]. There is also evidence that the survivors of stroke have some degree of residual motor sensory alteration

\footnotetext{
* Address correspondence to this author at the Clinical Research Center - Institute of Physical Medicine and Rehabilitation, University of Sao Paulo School of Medicine, São Paulo, São Paulo, Brazil; Tel: 55 (11) 3905-8616; E-mails: fabioalfieri@usp.br, fabio.alfieri@unasp.edu.br
} 
that adversely affects their balance and quality of life [20]. The worsening of balance can also be related to the increase in energy spent worrying about falling and the consequent fractures in those individuals [21].

It is noteworthy to highlight two questions about the maintenance of postural control: the first concerns the importance of the visual system that has the role of providing an external reference for the orientation of the body in relation to space, for during the aging process the visual acuity is progressively compromised [2, 3]. Reliance on vision to maintain postural control increases with age, especially in situations in which balance is challenged [18]. In a previous study we showed that the elderly that were considered healthy in the community showed worse results for postural control when their sight was suppressed [22]. In another study we showed the same result, but in frail elderly individuals [23]. It has been reported that, in the postural control of elderly individuals with stroke, there is more reliance on the visual system to control balance in relation to individuals in the control group [24].

The second question concerns postural control in individuals with stroke sequelae being influenced by the side of the brain that was affected. This question deserves to be investigated more deeply, for it is still a theme to be studied [18].There is conflict due to some results showing postural control being worse in individuals with injury on the right side of the brain and other results showing it is worse on the left side. However, there are also reports of the absence of difference between the affected sides [18]. As increased age is the most meaningful risk factor in the occurrence of a stroke $[25,26]$ and that, due to this and also to aging itself, mobility and balance are reduced and are related to falls, it is believed to be important to know the pattern of these variables in individuals considered healthy as well as in those with stroke sequelae, so that therapeutic activities may be better directed.

Within this context, the objective of this study was to verify and compare the pattern of functional mobility and postural control in elderly individuals considered healthy and elderly individuals with stroke sequelae.

\section{MATERIALS AND METHODS}

The local ethics committee approved the study (no. 0883/11) and all participants signed an informed consent form. This cross-sectional observational study was made in a rehabilitation center for outpatients in São Paulo, Brazil.

The participants were recruited at the Physical Medicine and Rehabilitation Institute (IMREA) of the Hospital of Clinics, School of Medicine of the University of São Paulo and Lucy Montoro Network, through verbal invitation. The control group (CG) was formed of individuals considered healthy who had the capacity to arrive at the place of evaluation independently. These individuals could be of both gender, aged at least 60 years, and who had not been engaged in any regular physical program of physical exercise/rehabilitation for three months before the evaluation. The individuals in the stroke sequelae group (SG) also could be of either gender and also aged at least 60 years. These were individuals who were participating in the rehabilitation program of the institute for at least three months or who had finished the program no more than three months before the evaluation. They also should be ambulatory. Individuals who presented paresis either on the right or on the left side were included.

This study did not allow individuals who showed severe insufficiencies such as: cardiac, coronary, respiratory, renal, or hepatic, or intense osteoporosis, symptomatic arthropathy, unstable diabetes. Those with articular prostheses and osteosyntheses (lower limb), with a history of previous fracture (especially in the lower limbs and vertebral column), with severe cognitive disorders that would impede the understanding of the evaluation activities, those without visual correction, with a history of dizziness, or with a recent history of falls also did not participate.

\section{Evaluation}

Initially, subjects were assessed with the Timed Up and Go (TUG) test, which requires a subject to stand up, walk $3 \mathrm{~m}$ (10 ft), turn, walk back, and sit down. The time taken to complete the test is strongly correlated with the level of functional mobility [27].The volunteer was instructed to "go" to perform the test and the time was recorded from the voice command until the time that the volunteer would support her back in the chair again. The test was performed once for familiarization and a second time to measure their time.

To measure the static postural control, the subjects were evaluated with a force platform (AMTI Inc, Watertown, MA) whereby the oscillation of the body center of pressure area could be defined, we assumed this parameter to represent the whole body oscillation [28, 29]. After calibration, signs of oscillation of the body were recorded with the platform in the bipedal position. During this assessment, subjects were asked to stand up in the bipedal position with eyes open and eyes closed for 1 minute - this was repeated three times. When vision was present, the subjects were asked to focus their sight on an object within 1 meter, at eye level. Participants were instructed to stand quietly 
throughout the duration of the test. Other environmental conditions like temperature and light were controlled and constant throughout the tests. The rater remained beside the subjects during the tests in order to prevent falls [28, 29].

Data were captured with Eva software (Hewlett Packard $®$, Palo Alto, CA), at a sampling frequency of $100 \mathrm{~Hz}$. The amplitude of movement $(\mathrm{cm})$ of the pressure center was assessed in the anteroposterior as well as lateromedial planes and were analyzed with Matlab ${ }^{\circledR}$ software (version 6.5). We used a routine developed in Matlab (version 6.5 ${ }^{\circledR}$; MathWorks, Upper Saddle River, NJ) to process the data [28, 29].

\section{Statistical Analysis}

The sample size calculation was determined by the study of Paillex and So [30] using a 5\% significance and $80 \%$ power, two-tailed. Data are presented as means \pm standard deviations. We used the Student $t$ test to check the differences between the two populations. The proportion for categorical variables was done using the Chi-square test. The Kruskal-Wallis Test with Dunn's Multiple Comparisons Test was performed on all the other comparisons in relation to body sway. When that there was normal distribution of data (where the variables on the balance in the anteroposterior direction between the left and right paretic sides were compared) an Analysis of variance (ANOVAKruskal-Wallis Test) was used. The significance level was 0.05. Data analysis was done using the GraphyPad Instat statistical package.

\section{RESULTS}

Twenty-four individuals were recruited for the group with stroke (SG), however, one of them was not able to walk without assistance and another five individuals did not come to the evaluation, leaving 18 participants in this group. Thirty-four individuals from the community who were considered healthy/control (CG), who were companions or friends of patients at the Institute, came to the evaluation.

The groups were similar in average age, but the BMI of the CG was higher than the SG. The proportion of females was higher in the control group when compared to the stroke group. This information as well as time of injury and the side of the paresis is shown in Table 1.

Table 1. General characteristics and result of functional mobility of participants (Mean \pm SD).

\begin{tabular}{|c|c|c|c|}
\hline & GS & GC & p \\
\hline $\mathrm{N}$ & 18 & 34 & $<0.0001^{*}$ \\
\hline $\mathrm{F} / \mathrm{M}$ & $6 / 12$ & $32 / 2$ & $0.44^{* *}$ \\
\hline Age (years) & $68.2 \pm 6.3$ & $69.5 \pm 5.4$ & $0.015^{* *}$ \\
\hline BMI (kg/cm2) & $25.3 \pm 2.03$ & $27.5 \pm 3.4$ & \\
\hline Time of lesion (months) & $33.9 \pm 24.7$ & - & \\
\hline Plegic side L/R & $8 / 10$ & - & \\
\hline
\end{tabular}

Notes: Values are presented as mean and standard deviation (SD). **unpaired $t$-test; Kg, kilogram; cm, centimeter; BMI, body mass index; F, female; M, male; GS, stroke group; GC control group; L, left; R, right; * chi-square; ** Student $t$ test.

Our findings reveal that the individuals in the SG showed worse results in their performance of the TUG test and in the displacement of center of pressure in the anteroposterior and mediolateral directions in the eyes open and closed conditions when compared to the CG. When we compared the intragroup results of the displacement of center of pressure, we observed that when visibility was suppressed, the results were worse, but only had statistical significance in the anteroposterior direction of the CG, as shown in Table 2.

Table 2. Comparison results of parameters of postural sway.

\begin{tabular}{|c|c|c|c|}
\hline & GS & GC & p \\
\hline TUG (s) & $32.21 \pm 24,56$ & $8.95 \pm 1.71$ & $<0.0001^{*}$ \\
\hline A/P displ (cm)-OE & $3.44 \pm 0.99$ & $2.81 \pm 1.02$ & $<0.001$ \\
\hline A/P displ (cm)-EC & $4.88 \pm 5.25$ & $3.42 \pm 1.33^{* *}$ & 0.05 \\
\hline M/L displ (cm)-OE & $2.53 \pm 1.45$ & $1.95 \pm 1.53$ & $<0.01$ \\
\hline M/L displ (cm)-EC & $2.85 \pm 1.87$ & $2.08 \pm 1.18$ & $<0.001$ \\
\hline
\end{tabular}

Note: TUG, timed up and go test; s, seconds; A/P, anteroposterior; displ, displacement of center of pressure; M/L, mediolateral; cm, centimeters; OE, open eyes; EC, eyes closed; * unpaired test $t$; ** $\mathrm{p}<0.001$ - intragroup relation OE x EC).

When comparing the results of the displacement of center of pressure in the anteroposterior and mediolateral 
directions with and without visibility, it was observed that the results were similar between the individuals that presented paresis on their right side and those on the left side, as shown in Table 3.

Table 3. Comparison results of parameters of postural sway between paretics sides: left $(L)$ and right (R).

\begin{tabular}{|c|c|c|c|}
\hline & GS- R & GS- L & p \\
\hline TUG (s) & $34.36 \pm 30.46$ & $29.45 \pm 9.29$ & NS \\
A/P displ (cm)-OE & $3.39 \pm 1.05$ & $3.39 \pm 0.86$ & NS \\
\hline A/P displ (cm)-EC & $3.61 \pm 1.32$ & $3.94 \pm 1,03$ & NS \\
\hline M/L displ (cm)-OE & $2.35 \pm 1.26$ & $2.62 \pm 1.63$ & NS \\
\hline M/L displ (cm)-EC & $2.78 \pm 1.29$ & $2.53 \pm 1.46$ & NS \\
\hline
\end{tabular}

Note: TUG, timed up and go test; s, seconds; A/P, anteroposterior; displ, displacement of center of pressure; M/L, mediolateral; cm, centimeters; OE, open eyes; EC, eyes closed; NS, no significant.

\section{DISCUSSION}

The results of this study showed that elderly individuals with stroke sequelae showed less postural control than elderly individuals who were considered healthy.

Some studies verified the question of postural control in healthy elderly individuals who participated in exercise programs to improve this control, [31 - 34] and other studies verified the influence of the many programs for rehabilitation of postural control in individuals with stroke sequelae [35 - 41]. Some studies sought to verify the aspects of postural control in individuals with stroke sequelae $[42,43]$ while others compared the postural control in relation to a control group [44]. Similarly, to the present study, Marigold and Eng [24] verified the postural control in elderly individuals, however divided into one group with stroke sequelae and a control group.

In this study, we investigated the balance due to its importance, for it is established that the static and dynamic balances are fundamental for the execution of daily activities of the elderly. However, the loss of balance is frequent and in addition to increasing the energy use, it may be directly associated with falls and high risk of fractures in the elderly, especially those elderly with stroke sequelae [21].

The static balance is very important because it is a predictor of independence and also of the risk of falling for the elderly [33]. To evaluate it, we preferred to use the objective data provided by the force platform [21]. This evaluation at rest of the displacement of center of pressure in the mediolateral and anteroposterior directions reflects the muscular action to maintain the balance of the orthostatic posture. When the center of pressure shows a reduced amplitude of movement, this reflects a good balance control, while a wide amplitude of movement reflects a poor control of postural balance $[2,3,34]$. The results of this study showed that elderly individuals with stroke sequelae present worse static balance when compared to healthy elderly individuals, which makes us believe that they exert greater muscular effort to maintain the bipedal posture.

An example of that is the use of the ankle muscles (dorsiflexors and plantar flexors) for the stabilization in the anteroposterior direction in the orthostatic position [45]. These muscles are the first to be lost in the elderly due to muscular weakness and to peripheral sensory loss [3]. That may explain why when sight was removed during the balance tests, this direction (anteroposterior) was the one with the worst results, even for the healthy elderly individuals, which was surprising. We also highlight that sight is an important factor in postural control of healthy individuals and of those with stroke sequelae, confirming that in situations where visibility is suppressed, the results for postural control tend to be worse than when it is allowed $[33,46]$.

Similarly to the present study, Marigold and Eng [24] verified the postural control in the elderly with and without stroke sequelae, but the authors found that the individuals with stroke sequelae were more dependent on their sight to maintain postural control in relation to the speed of movement in the mediolateral direction, but not in the anteroposterior direction, in relation to the control group. However, in our study we were able to verify that regardless of visibility, the individuals in the SG showed worse results for the range of movement in the anteroposterior as well as in the mediolateral direction when compared to the control group.

As for the Timed up and go test [27]that was used to verify the dynamic balance, it was completed in less time by the healthy individuals. This happened probably due to the better musculoskeletal conditions such as the strength of the limbs, but also due to the better afferent sensory information. This is because the functional loss of the lower limbs due to stroke is not due simply to the paresis/lack of muscular strength, but also due to the lack of articular stability and loss of proprioception [47]. 
As for the time in performing the TUG, independent adult individuals with no balance alterations can perform the test in 10 seconds or less; those dependent on basic transferences can perform it in 20 seconds or less, and those who need more than 20 seconds are dependent in many daily life activities and in their mobility, indicating the need for a suitable therapeutic intervention [27]. A meta-analysis of the reference values from the TUG test verified that individuals aged over 60 years perform the test on an average of 9.4 seconds [48]. If we look to the average time to perform the TUG shown by the healthy elderly, 8.95 seconds, we see that it is a little below average, since the average time for the participants of the stroke sequelae group, which was 32.21 seconds, is compatible with the loss of daily life activities and mobility, which would call for a more specific intervention to improve mobility.

As for the injury side, it was seen in this study that individuals with the paretic limb on the right or left sides showed the same level of dynamic as well as static control, showing that the sequelae regarding the capacity for postural control had no relation to which side was affected, and is in agreement with the studies of Bonan et al. [49] and De Haart et al. [50] therefore, they contest the concept that individuals with postural control problems are those who have cerebral injuries on the right side [51 - 56].

As there is still no concrete evidence on the best way to reestablish balance after a stroke, [57] we believe that the proprioceptive stimuli, as well as the improvement in the muscular performance of the dorsiflexors and plantar flexors must be prioritized during the rehabilitation process in order to diminish the oscillation in the anteroposterior direction. Another factor that also must be taken into consideration in relation to the rehabilitation is the improvement in the mediolateral stability that is related to the hip musculature $[3,58]$. It is believed that this musculature must also be emphasized, for many activities that place the elderly at risk of falling also involve movements in the lateral direction [59]. That is, to improve the balance of healthy elderly and of those with stroke sequelae, it is necessary, in addition to articular stability and sensory stimuli, to improve the muscular action of the ankles as well as of the hips.

Each hemiparetic individual has a unique combination of postural abnormalities and the stroke can affect different functions independently or in tandem, causing a wide-ranging loss of compensation strategies in each individual [18]. In this sense, we believe that future studies that evaluate other sensory systems, in addition to the static and dynamic balances such as the vestibular, in addition to the evaluation of flexibility and muscular strength in the region of the ankles, as well as the shifting of weight and the level of spasticity, may provide more information on the aspects that involve the postural control of elderly individuals with and without stroke. In this study, we saw the difference in the number of females and males in both groups as a probable limiting factor, and because of that, we believe a study comparing the influence of gender on postural control could shed new light on the subject.

Finally, a factor to be considered is the question of the evaluation in this study having been made without the help of an occasional orthosis used voluntarily. Although the volunteers in this study were persons who walked without the help of orthoses, it is believed that as hemiparetic individuals use such devices occasionally, a future study comparing the balance of this type of volunteer with and without an orthosis may also provide not only a better understanding of postural control, but also better evidence for the recommendation of orthoses for the gait.

It was concluded in this study that individuals with stroke sequelae showed worse results for the static as much as for the dynamic postural control in relation to the elderly of the same age considered as healthy. We can also affirm that in both groups there was a reduction of postural control when sight was not present, especially in the anteroposterior direction when compared to the healthy elderly group. In relation to the side of the brain in the cerebral injury, there was also no difference in the performance for the dynamic as well as for the static balance.

\section{CONFLICT OF INTEREST}

The authors confirm that this article content has no conflict of interest.

\section{ACKNOWLEDGEMENTS}

To Denise Alcalde Salzedas and to the team at the research center for their help in recruiting volunteers for this study.

This study was developed as part of the NAP-NEAR-USP activities. 


\section{REFERENCES}

[1] Duarte M, Sternad D. Complexity of human postural control in young and older adults during prolonged standing. Exp Brain Res 2008; 191(3): 265-76.

[http://dx.doi.org/10.1007/s00221-008-1521-7] [PMID: 18696056]

[2] Alexander NB. Postural control in older adults. J Am Geriatr Soc 1994; 42(1): 93-108. [http://dx.doi.org/10.1111/j.1532-5415.1994.tb06081.x] [PMID: 8277123]

[3] Shumway-Cook A, Woollacott M. Motor control: theory and practical applications. Baltimore: Williams and Wilkins 1995.

[4] Konrad HR, Girardi M, Helfert R. Balance and aging. Laryngoscope 1999; 109(9): 1454-60. [http://dx.doi.org/10.1097/00005537-199909000-00019] [PMID: 10499055]

[5] Jones GM. Movement Part VI. Posture. In: Kandel ER, Schwartz J, Jessell TM, Eds. Principles of neural science. $4^{\text {th }}$ ed. USA: Mc Graw Hill 2000

[6] Kronhed A-C, Moller C, Olsson B, Moller M. The effect of short-term balance training on community dwelling older adults. J Aging Phys Act 2001; 9: 19-31.

[7] Carter ND, Kannus P, Khan KM. Exercise in the prevention of falls in older people: a systematic literature review examining the rationale and the evidence. Sports Med 2001; 31(6): 427-38

[http://dx.doi.org/10.2165/00007256-200131060-00003] [PMID: 11394562]

[8] Shaffer SW, Harrison AL. Aging of the somatosensory system: a translational perspective. Phys Ther 2007; 87(2): 193-207. [http://dx.doi.org/10.2522/ptj.20060083] [PMID: 17244695]

[9] Booth FW, Weeden SH, Tseng BS. Effect of aging on human skeletal muscle and motor function. Med Sci Sports Exerc 1994; 26(5): 556-60. [http://dx.doi.org/10.1249/00005768-199405000-00006] [PMID: 8007802]

[10] Thornell LE, Lindström M, Renault V, Mouly V, Butler-Browne GS. Satellite cells and training in the elderly. Scand J Med Sci Sports 2003; 13(1): 48-55.

[http://dx.doi.org/10.1034/j.1600-0838.2003.20285.x] [PMID: 12535317]

[11] Williams GN, Higgins MJ, Lewek MD. Aging skeletal muscle: physiologic changes and the effects of training. Phys Ther 2002; 82(1): 62-8. [PMID: 11784279]

[12] Hobeika CP. Equilibrium and balance in the elderly. Ear Nose Throat J 1999; 78(8): 558-62, 565-6. [PMID: 10485148]

[13] Wolfe CD. The impact of stroke. Br Med Bull 2000; 56(2): 275-86. [http://dx.doi.org/10.1258/0007142001903120] [PMID: 11092079]

[14] Langhorne P, Bernhardt J, Kwakkel G. Stroke rehabilitation. Lancet 2011; 377(9778): 1693-702. [http://dx.doi.org/10.1016/S0140-6736(11)60325-5] [PMID: 21571152]

[15] Costa AR, Silva F, Andrade LA. Acidentes vasculares cerebrais. Rev Bras Med 2005; 62(6): 224-30.

[16] Warlow CP, van Gijn J, Dennis MS, et al. Stroke: practical management. $3^{\text {rd }}$ ed. Oxford: Blackwell Publishing 2008. [http://dx.doi.org/10.1002/9780470696361]

[17] Bonita R, Mendis S, Truelsen T, Bogousslavsky J, Toole J, Yatsu F. The global stroke initiative. Lancet Neurol 2004; 3(7): 391-3. [http://dx.doi.org/10.1016/S1474-4422(04)00800-2] [PMID: 15207791]

[18] de Oliveira CB, de Medeiros IR, Frota NA, Greters ME, Conforto AB. Balance control in hemiparetic stroke patients: main tools for evaluation. J Rehabil Res Dev 2008; 45(8): 1215-26. [http://dx.doi.org/10.1682/JRRD.2007.09.0150] [PMID: 19235121]

[19] Chen IC, Cheng PT, Chen CL, Chen SC, Chung CY, Yeh TH. Effects of balance training on hemiplegic stroke patients. Chang Gung Med J 2002; 25(9): 583-90

[PMID: 12479619]

[20] Garland SJ, Gray VL, Knorr S. Muscle activation patterns and postural control following stroke. Mot Contr 2009; 13(4): $387-411$. [PMID: 20014647]

[21] Yavuzer G. Postural control in hemiparetic patients after stroke. FTR Bil Der J PMR Sci 2006; 9(3): 76-9.

[22] Guirro RRJ, Teodori RM. Postural stability of elderly submmitted to multissensorial physical therapy intervention. Electromyogr Clin Neurophysiol 2010; 50: 113-9. [PMID: 20405787]

[23] Alfieri FM, Riberto M, Abril-Carreres A, et al. Effectiveness of an exercise program on postural control in frail older adults. Clin Interv Aging 2012; 7: 593-8

[http://dx.doi.org/10.2147/CIA.S36027] [PMID: 23269865]

[24] Marigold DS, Eng JJ. The relationship of asymmetric weight-bearing with postural sway and visual reliance in stroke. Gait Posture 2006; 23(2): 249-55.

[http://dx.doi.org/10.1016/j.gaitpost.2005.03.001] [PMID: 16399522] 
[25] National Institute of Health. National Institute of Neurological Disorders and Stroke (NINDS). Office of Communication and Public Liason. Stroke: hope through research. Bethesda, Md. : The Institute 1999.

[26] Martin JE, Sheaff MT. The pathology of ageing: concepts and mechanisms. J Pathol 2007; 211(2): 111-3. [http://dx.doi.org/10.1002/path.2122] [PMID: 17200949]

[27] Podsiadlo D, Richardson S. The timed "Up \& Go": a test of basic functional mobility for frail elderly persons. J Am Geriatr Soc 1991; 39(2): $142-8$.

[http://dx.doi.org/10.1111/j.1532-5415.1991.tb01616.x] [PMID: 1991946]

[28] Raymakers JA, Samson MM, Verhaar HJ. The assessment of body sway and the choice of the stability parameter(s). Gait Posture 2005; 21(1): 48-58. [http://dx.doi.org/10.1016/j.gaitpost.2003.11.006] [PMID: 15536033]

[29] Duarte M, Freitas SM. Revision of posturography based on force plate for balance evaluation. Rev Bras Fisioter 2010; 4(3): 183-92. [http://dx.doi.org/10.1590/S1413-35552010000300003] [PMID: 20730361]

[30] Paillex R, So A. Posture debout chez des sujets adultes: spécificités de l'hémiplégie. Ann Readapt Med Phys 2003; 46(2): 71-8. [Standing posture of adults: effects of a stroke]. [http://dx.doi.org/10.1016/S0168-6054(03)00002-3] [PMID: 12676410]

[31] Alfieri FM, Riberto M, Gatz LS, Ribeiro CP, Lopes JA, Battistella LR. Comparison of multisensory and strength training for postural control in the elderly. Clin Interv Aging 2012; 7: 119-25.

[http://dx.doi.org/10.2147/CIA.S27747] [PMID: 22654512]

[32] Alfieri FM, Riberto M, Gatz LS, Ribeiro CP, Lopes JA, Battistella LR. Functional mobility and balance in community-dwelling elderly submitted to multisensory versus strength exercises. Clin Interv Aging 2010; 5: 181-5. [http://dx.doi.org/10.2147/CIA.S10223] [PMID: 20711437]

[33] Rogers ME, Rogers NL, Takeshima N, Islam MM. Methods to assess and improve the physical parameters associated with fall risk in older adults. Prev Med 2003; 36(3): 255-64. [http://dx.doi.org/10.1016/S0091-7435(02)00028-2] [PMID: 12634016]

[34] Howe TE, Rochester L, Jackson A, Banks PM, Blair VA. Exercise for improving balance in older people. Cochrane Database Syst Rev 2007; 17: CD004963.

[http://dx.doi.org/10.1002/14651858.CD004963.pub2]

[35] Lubetzky-Vilnai A, Kartin D. The effect of balance training on balance performance in individuals poststroke: a systematic review. J Neurol Phys Ther 2010; 34(3): 127-37. [http://dx.doi.org/10.1097/NPT.0b013e3181ef764d] [PMID: 20716987]

[36] Billot M, Handrigan GA, Simoneau M, Corbeil P, Teasdale N. Short term alteration of balance control after a reduction of plantar mechanoreceptor sensation through cooling. Neurosci Lett 2013; 535: 40-4. [http://dx.doi.org/10.1016/j.neulet.2012.11.022] [PMID: 23305721]

[37] Tung FL, Yang YR, Lee CC, Wang RY. Balance outcomes after additional sit-to-stand training in subjects with stroke: a randomized controlled trial. Clin Rehabil 2010; 24(6): 533-42.

[http://dx.doi.org/10.1177/0269215509360751] [PMID: 20410150]

[38] Au-Yeung SS, Hui-Chan CW, Tang JC. Short-form Tai Chi improves standing balance of people with chronic stroke. Neurorehabil Neural Repair 2009; 23(5): 515-22. [http://dx.doi.org/10.1177/1545968308326425] [PMID: 19129308]

[39] Eng JJ, Chu KS, Kim CM, Dawson AS, Carswell A, Hepburn KE. A community-based group exercise program for persons with chronic stroke. Med Sci Sports Exerc 2003; 35(8): 1271-8. [http://dx.doi.org/10.1249/01.MSS.0000079079.58477.0B] [PMID: 12900678]

[40] Noh DK, Lim JY, Shin HI, Paik NJ. The effect of aquatic therapy on postural balance and muscle strength in stroke survivors--a randomized controlled pilot trial. Clin Rehabil 2008; 22(10-11): 966-76.

[http://dx.doi.org/10.1177/0269215508091434] [PMID: 18955428]

[41] Saeys W, Vereeck L, Truijen S, Lafosse C, Wuyts FP, Heyning PV. Randomized controlled trial of truncal exercises early after stroke to improve balance and mobility. Neurorehabil Neural Repair 2012; 26(3): 231-8. [http://dx.doi.org/10.1177/1545968311416822] [PMID: 21844283]

[42] Kirker SG, Jenner JR, Simpson DS, Wing AM. Changing patterns of postural hip muscle activity during recovery from stroke. Clin Rehabil 2000; 14(6): 618-26.

[http://dx.doi.org/10.1191/0269215500cr370oa] [PMID: 11128737]

[43] Sackley CM. Falls, sway, and symmetry of weight-bearing after stroke. Int Disabil Stud 1991; 13(1): 1-4. [http://dx.doi.org/10.3109/03790799109166267] [PMID: 1917796]

[44] Bensoussan L, Viton JM, Schieppati M, et al. Changes in postural control in hemiplegic patients after stroke performing a dual task. Arch Phys Med Rehabil 2007; 88(8): 1009-15.

[http://dx.doi.org/10.1016/j.apmr.2007.05.009] [PMID: 17678663] 
[45] Thelen DG, Schultz AB, Alexander NB, Ashton-Miller JA. Effects of age on rapid ankle torque development. J Gerontol A Biol Sci Med Sci 1996; 51(5): M226-32. [http://dx.doi.org/10.1093/gerona/51A.5.M226] [PMID: 8808994]

[46] Perrin PP, Gauchard GC, Perrot C, Jeandel C. Effects of physical and sporting activities on balance control in elderly people. Br J Sports Med 1999; 33(2): 121-6. [http://dx.doi.org/10.1136/bjsm.33.2.121] [PMID: 10205695]

[47] Park YH, Kim YM, Lee BH. An ankle proprioceptive control program improves balance, gait ability of chronic stroke patients. J Phys Ther Sci 2013; 25(10): 1321-4. [http://dx.doi.org/10.1589/jpts.25.1321] [PMID: 24259785]

[48] Bohannon RW. Reference values for the timed up and go test: a descriptive meta-analysis. J Geriatr Phys Ther 2006; 29(2): 64-8. [http://dx.doi.org/10.1519/00139143-200608000-00004] [PMID: 16914068]

[49] Bonan IV, Colle FM, Guichard JP, et al. Reliance on visual information after stroke. Part I: Balance on dynamic posturography. Arch Phys Med Rehabil 2004; 85(2): 268-73. [http://dx.doi.org/10.1016/j.apmr.2003.06.017] [PMID: 14966712]

[50] de Haart M, Geurts AC, Huidekoper SC, Fasotti L, van Limbeek J. Recovery of standing balance in postacute stroke patients: a rehabilitation cohort study. Arch Phys Med Rehabil 2004; 85(6): 886-95. [http://dx.doi.org/10.1016/j.apmr.2003.05.012] [PMID: 15179641]

[51] Pérennou D, Bénaïm C, Rouget E, Rousseaux M, Blard JM, Pélissier J. Postural balance following stroke: towards a disadvantage of the right brain-damaged hemisphere. Rev Neurol (Paris) 1999; 155(4): 281-90. [PMID: 10367325]

[52] Rode G, Tiliket C, Boisson D. Predominance of postural imbalance in left hemiparetic patients. Scand J Rehabil Med 1997; 29(1): 11-6. [PMID: 9084100]

[53] Bohannon RW, Smith MB, Larkin PA. Relationship between independent sitting balance and side of hemiparesis. Phys Ther 1986; 66(6): 944-5.

[54] Heilman KM, Bowers D, Valenstein E, Watson RT. The right hemisphere: neuropsychological functions. J Neurosurg 1986; 64(5): 693-704. [http://dx.doi.org/10.3171/jns.1986.64.5.0693] [PMID: 3517248]

[55] Ustinova KI, Chernikova LA, Ioffe ME, Sliva SS. Impairment of learning the voluntary control of posture in patients with cortical lesions of different locations: the cortical mechanisms of pose regulation. Neurosci Behav Physiol 2001; 31(3): 259-67. [http://dx.doi.org/10.1023/A:1010326332751] [PMID: 11430569]

[56] Peurala SH, Könönen P, Pitkänen K, Sivenius J, Tarkka IM. Postural instability in patients with chronic stroke. Restor Neurol Neurosci 2007; 25(2): 101-8. [PMID: 17726268]

[57] Geurts AC, de Haart M, van Nes IJ, Duysens J. A review of standing balance recovery from stroke. Gait Posture 2005; 22 (3): 267-81. [http://dx.doi.org/10.1016/j.gaitpost.2004.10.002] [PMID: 16214666]

[58] Nagy E, Feher-Kiss A, Barnai M, Domján-Preszner A, Angyan L, Horvath G. Postural control in elderly subjects participating in balance training. Eur J Appl Physiol 2007; 100(1): 97-104. [http://dx.doi.org/10.1007/s00421-007-0407-x] [PMID: 17333243]

[59] Islam MM, Nasu E, Rogers ME, Koizumi D, Rogers NL, Takeshima N. Effects of combined sensory and muscular training on balance in Japanese older adults. Prev Med 2004; 39(6): 1148-55. [http://dx.doi.org/10.1016/j.ypmed.2004.04.048] [PMID: 15539049]

Received: June 29, $2015 \quad$ Revised: August 1, 2015 Accepted: September 11, 2015

(C) Alfieri et al.; Licensee Bentham Open.

This is an open access article licensed under the terms of the Creative Commons Attribution-Non-Commercial 4.0 International Public License (CC BY-NC 4.0) (https://creativecommons.org/licenses/by-nc/4.0/legalcode), which permits unrestricted, non-commercial use, distribution and reproduction in any medium, provided the work is properly cited. 